Original Research Article

\title{
The haemato-protective effect of Piliostigma thonningii leaf extract on indomethacin-induced gastric mucosa ulcer in rats
}

\author{
A. A. Asuk*, K. Dasofunjo, M. N. Ugwu, F. O. Adie
}

\begin{abstract}
Department of Medical
Biochemistry, Faculty of Basic

Medical Sciences, Cross River

University of Technology,

Okuku Campus, Nigeria
\end{abstract}

Received: 05 June 2018

Accepted: 28 June 2018

*Correspondence to:

Dr. A. A. Asuk,

Email: raphaelasuk@gmail.com

Copyright: (C) the author(s), publisher and licensee Medip Academy. This is an openaccess article distributed under the terms of the Creative Commons Attribution NonCommercial License, which permits unrestricted noncommercial use, distribution, and reproduction in any medium, provided the original work is properly cited.

\begin{abstract}
Background: Gastric ulcer is a common gastrointestinal disorder with global consequence, which is aggravated by an imbalance between the aggressive factors and factors that maintain the mucosal integrity. The role of Piliostigma thonningii leaf extract on hematological indices of indomethacin-induced gastric mucosa lesions in Wistar rats was examined.

Methods: Thirty-six male rats were divided into six groups of 6 rats each. Group I, the normal control, II gastric ulcerated + cimetidine (standard control), III extract only $(100 \mathrm{mg} / \mathrm{kg}$ bwt), while IV, gastric ulcerated control, V gastric ulcerated + extract $(100 \mathrm{mg} / \mathrm{kg}$ bwt $)$ and VI gastric ulcerated + extract $(200 \mathrm{mg} / \mathrm{kg}$ bwt). After 12 days of administration, gastric ulcer was then induced by oral administration of $40 \mathrm{mg} / \mathrm{kg}$ bwt indomethacin to rats in groups II, IV, V and VI. The rats were sacrificed 12 hours after indomethacin treatment and blood collected for hematological assay.

Results: The $\mathrm{RBC}$ count and $\mathrm{Hb}$ pattern were similar. There was a significant $(\mathrm{P}<0.05)$ decrease in $\mathrm{RBC}$ and $\mathrm{Hb}$ of the ulcer control group which was normalized on administration of $200 \mathrm{mg} / \mathrm{kg}$ bwt of $P$. thonningii extract. The $\mathrm{MCV}$ of the ulcer lesion was significantly $(\mathrm{P}<0.05)$ reversed to normal by the extract.

Conclusions: The $P$. thonningii leaf extract showed promising result by normalizing decreased levels in $\mathrm{RBC}$ and $\mathrm{Hb}$ caused by ulcer. Except for platelet counts, the WBC count and differential WBC counts were quite positive. It was able to reverse macrocytosis caused by ulcer lesions to normal, hence exhibiting a hemato-protective nature.
\end{abstract}

Keywords: Blood indices, Erythropoiesis, Macrocytosis, Plant extract, Thrombocytopenia

\section{INTRODUCTION}

An ulcer is basically an inflamed break in the skin or mucus lining of the alimentary tract. Ulceration occurs when there is a disturbance of the normal equilibrium caused by either enhanced aggression or diminished mucosal resistance. ${ }^{1}$ About 19 out of 20 peptic ulcers are duodenal while gastric ulcers found in the stomach wall are less common. ${ }^{2}$ The pathogenesis of ulcer remains controversial but its cause is known to be aggravated by an imbalance between the aggressive factors (i.e. acids, pepsin, and Helicobacter pylori) and factors that maintain the mucosal integrity (mucus, bicarbonate, and prostaglandin). ${ }^{3}$ The gastric mucosa is continuously exposed to potentially injurious agents such as acids, pepsin, bile acids, food ingredients, bacterial products $(H$. pylori) and drugs. ${ }^{4}$

These agents have been implicated in the pathogenesis of gastric ulcer, including enhanced gastric acid and pepsin, inhibition of prostaglandin synthesis and cell proliferation growth diminished gastric blood flow and gastric motility. ${ }^{4}$ Current management of peptic ulcer disease involves the use of Proton Pump Inhibitor (PPI), antibiotic and metronidazole (triple therapy). ${ }^{5}$ High cost of treatment and unbearable side effects of the conventional anti-ulcer drugs lead to poor compliance and resultant treatment 
failures. There is therefore needing to develop safer, more effective and affordable alternatives in the symptomatic management of ulcer disease.

More so, the World Health Organization (WHO) estimates that over 4 billion people or $80 \%$ of the world's population use herbal medicine for some aspects of primary health care. ${ }^{6}$ A typical example of such herbal plant is Piliostigma thonningii, in which extracts of the plant have been used in the management of several ailments including cough, skin rashes, gonorrhoea, menorrhagia, and attributed with antibacterial and antioxidant properties, hypolipidemic and haematopoietic effects among others. ${ }^{7-10}$ Therefore, the present study investigated the possible use of $P$. thonningii extract in the management and possible protection against haematological breakdown arising from gastric ulcerative lesions of male Wistar rats.

\section{METHODS}

\section{Plant material}

Fresh leaves of $P$. thonningii were collected along OgojaKatsina-Ala highway of Cross River State, Nigeria. The leaves were taken to Federal College of Forestry (FCOFJ) Jos in Plateau State, Department of Herbarium for identification and authentication with the Voucher number \#25 and specimen deposited for future reference at the Department's Herbarium.

\section{Preparation of the leaf extract}

Fresh leaves of $P$. thonningii were air-dried at room temperature for about 20 days, pulverized and homogenized into powder using blender. Three hundred grams $(300 \mathrm{~g})$ of the powdered $P$. thonningii leaves were dissolved in $1200 \mathrm{~mL}$ of $75 \%$ ethanol and kept in a refrigerator for 24 hours. Thereafter, it was filtered with muslin cloth firstly and then with Whatman No.1 filter paper. The filtrate was evaporated to dryness and the percentage yield was calculated.

\section{Experimental animal}

Thirty-six (36) Wistar rats of 150-200g were obtained from the Animal Holding Unit of the Department of Medical Biochemistry, Cross River University of Technology, Cross River State, Nigeria. The animals were allowed to undergo acclimatization for seven days before the commencement of the research.

The rats were housed in wooden cages. The animal room was well ventilated and kept at room temperature of $29 \pm 2{ }^{\circ} \mathrm{C}$ and $70 \%$ relative humidity with 12 -hour natural light-dark cycle and allowed free access to rat chow and water ad libitum. Good hygiene was maintained by constant cleaning and changing of the beddings daily. All animals were handled in accordance with the guidelines of the European Convention for the Protection of Vertebrate animals and other scientific purposes-ETS-123. ${ }^{11}$

\section{Experimental design}

The experiment was carried out on 36 male rats that were divided into six groups of 6 rats each. Group I served as control and was given $0.5 \mathrm{~mL}$ of normal saline (vehicle). Group III were given $100 \mathrm{mg} / \mathrm{kg}$ body weight of extract only while groups V and VI were administered 100 and $200 \mathrm{mg} / \mathrm{kg}$ body weight of the aqueous extract respectively to ulcer-induced rats. Group II was treated with $100 \mathrm{mg} / \mathrm{kg}$ body weight of cimetidine (standard drug). Whereas the extract and vehicle were administered orally, cimetidine was administered intra-muscularly for 12 days consecutively. After 12 days of the last administration all rats were fasted for 24 hours, gastric ulceration was then induced by oral administration of $40 \mathrm{mg} / \mathrm{kg}$ body weight of indomethacin to animals of groups II, IV, V, and VI respectively. Twelve (12) hours after indomethacin administration all rats were sacrificed, and blood collected by cardiac puncture into heparinized vacutainers for haematological evaluation.

\section{Determination of haematological profile}

The method of The Horiba ABX 80 Diagnostics, ABX pentra Montpellier, France was used for the determination of red blood cells (RBC), haemoglobin ( $\mathrm{Hb})$, haematocrit (HCT) or packed cell volume (PCV), mean corpuscular volume (MCV), mean corpuscular haemoglobin $(\mathrm{MCH})$, mean corpuscular haemoglobin concentration (MCHC). Other are white blood cell (WBC) count, neutrophils, lymphocytes, mixed cell count or MXD (eosinophils, basophils and monocytes) and platelets.

\section{Statistical analysis}

Data obtained was analysed using Microsoft Excel 2007 and expressed as mean \pm SD. The statistical package SPSS version 17 was used to establish statistical significance at $\mathrm{P}<0.05$.

\section{RESULTS}

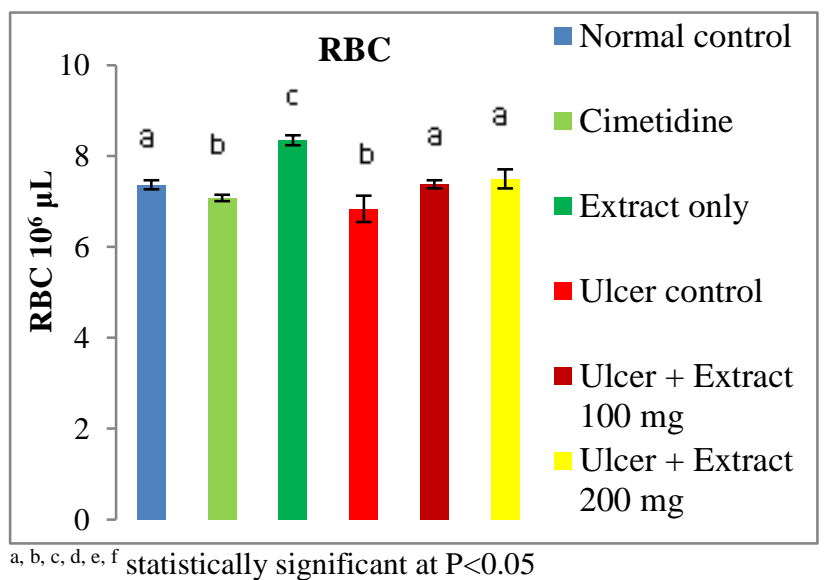

Figure 1: RBC count of indomethacin mediated gastric mucosa lesion in Wistar rats on administration of $P$. thonningii extract. 
The results below revealed the protective effect of $P$. thonningii leaf extract on haematological profile of indomethacin-induced mucosa gastric ulcer in male Wistar rats. The results for red blood cell (RBC) count and haemoglobin $(\mathrm{Hb})$ showed a similar pattern as the administration of the extract only showed significant $(\mathrm{P}<0.05)$ increase compared with the rest of the groups. There was also a significant $(\mathrm{P}<0.05)$ decrease in $\mathrm{RBC}$ of the ulcer control group which was normalised on administration of $200 \mathrm{mg} / \mathrm{kg}$ bwt of $P$. thonningii extract (Figure 1). A similar pattern was also seen with $\mathrm{Hb}$ (Figure 2).

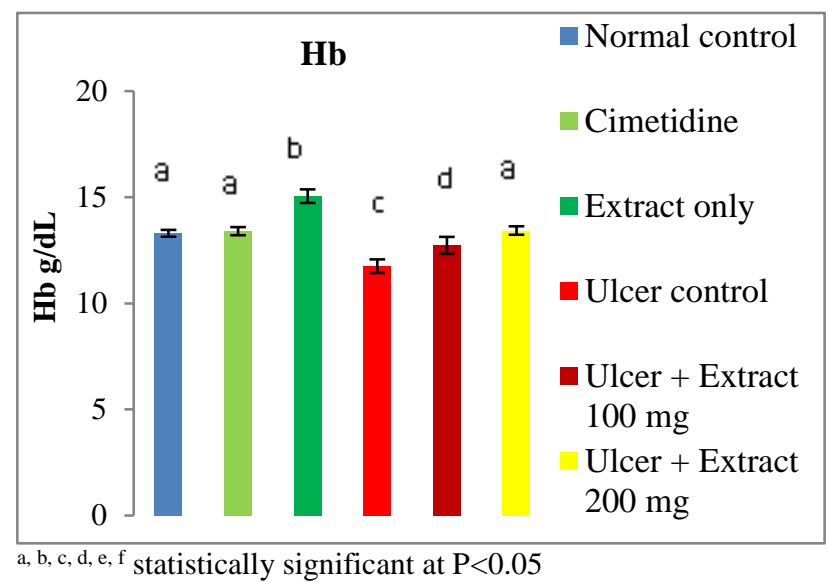

Figurer 2: Hb concentration of indomethacin mediated gastric mucosa lesion in Wistar rats on administration of $\boldsymbol{P}$. thonningii extract.

The haematocrit (HCT) or packed cell volume (PCV) was significantly increased when the $P$. thonningii extract was administered to ulcerative lesions at $100 \mathrm{mg}$ and $200 \mathrm{mg}$ compared with the rest of the groups (Figure 3).

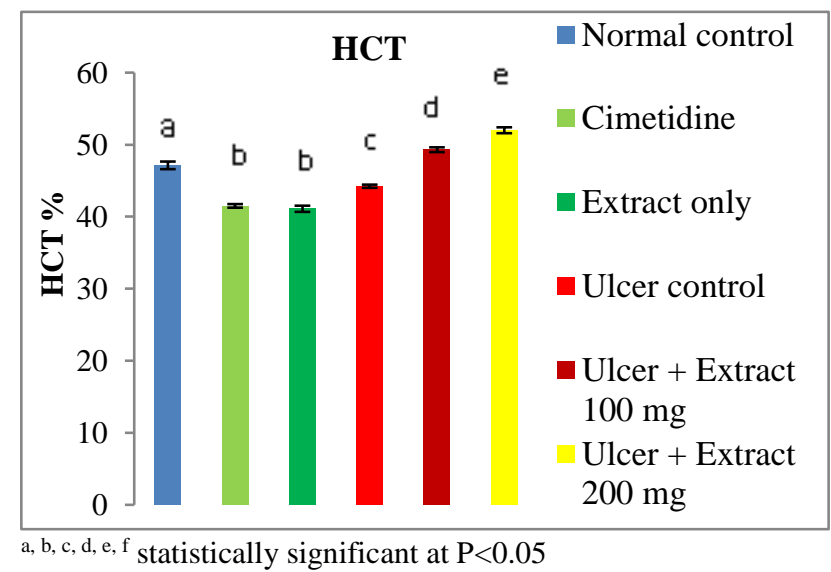

Figure 3: HCT concentration of indomethacin mediated gastric mucosa lesion in Wistar rats on administration of $\boldsymbol{P}$. thonningii extract.

The mean corpuscular volume (MCV) (Figure 4) was normalised but not mean corpuscular haemoglobin (MCH) (Figure 5) or mean corpuscular haemoglobin concentration (MCHC) (Figure 6) when $200 \mathrm{mg} / \mathrm{kg}$ bwt of P.thonningii extract was administered to ulcer lesions, whereas the platelet count (Figure 7) was significantly decreased in all the groups compared with the normal control. However, the platelet count for the ulcer treated groups with $P$. thonningii extract were further decreased.

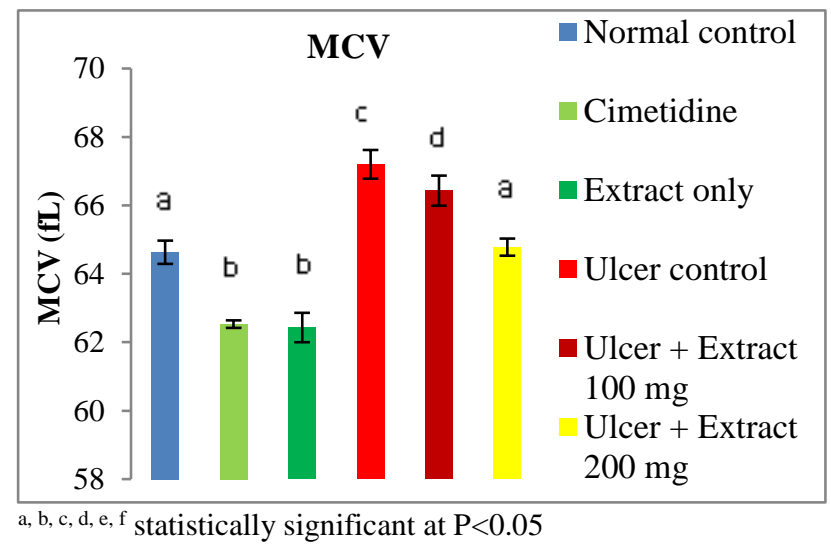

Figure 4: MCV concentration of indomethacin mediated gastric mucosa lesion in Wistar rats on administration of $P$. thonningii extract.

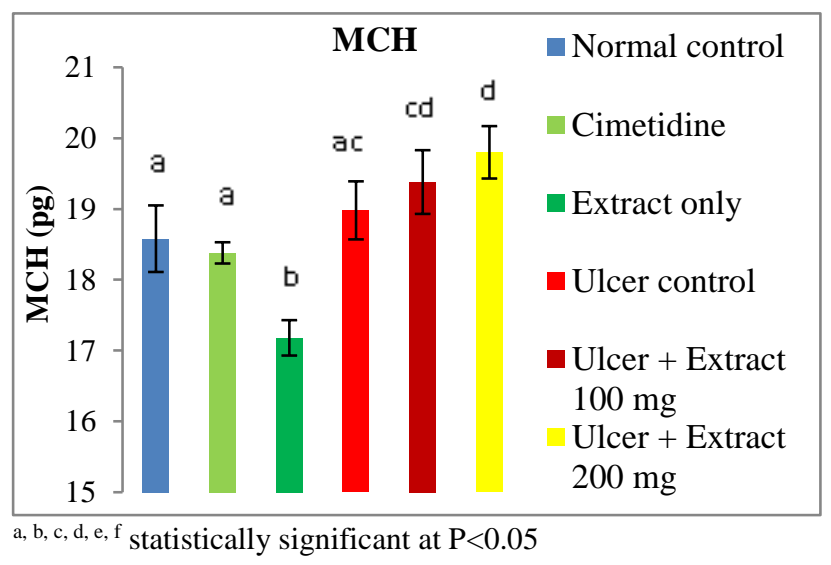

Figure 5: MCH concentration of indomethacinmediated gastric mucosa lesion in Wistar rats on administration of $P$. thonningii extract.

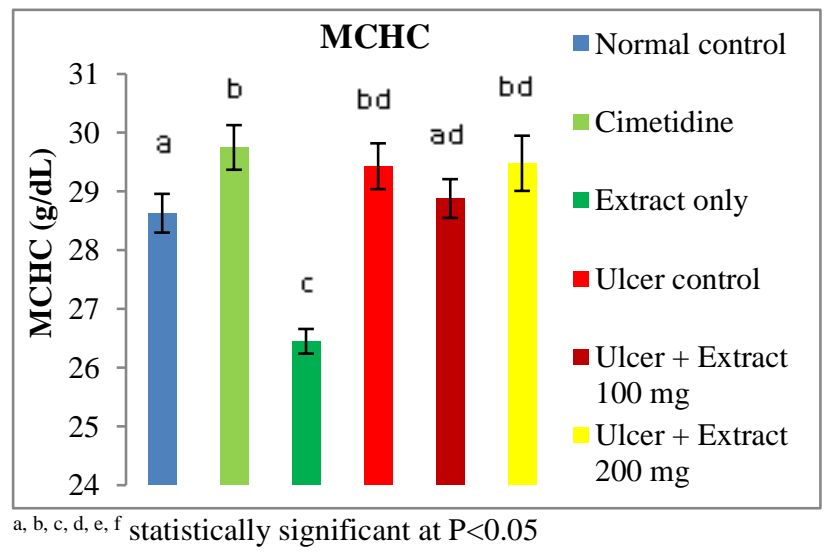

Figure 6: MCHC concentration of indomethacin mediated gastric mucosa lesion in Wistar rats on administration of $P$. thonningii extract. 
There was significant $(\mathrm{P}<0.05)$ increase in WBC count when $200 \mathrm{mg} / \mathrm{kg}$ bwt of $P$. thonningii extract was administered to gastric mucosa ulcerated lesions compared with the rest of the groups (Figure 8).

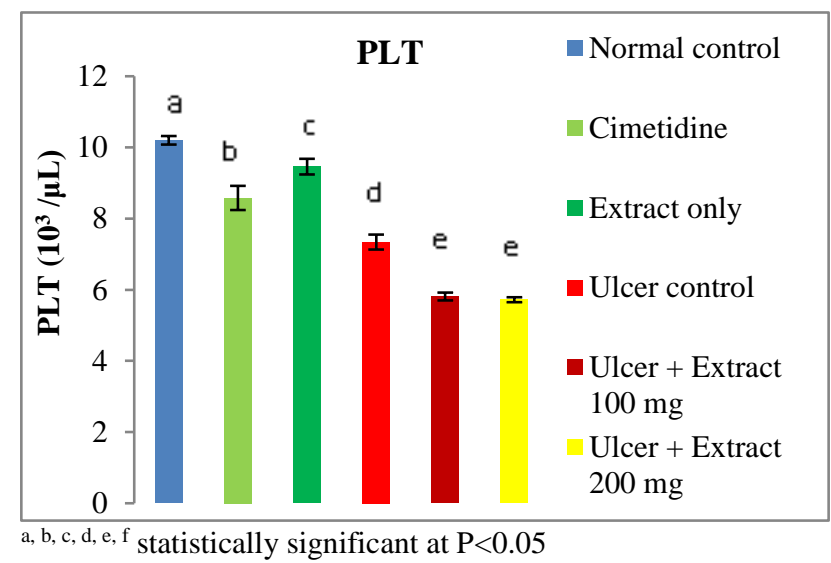

Figure 7: PLT concentration of indomethacin mediated gastric mucosa lesion in Wistar rats on administration of $P$. thonningii extract.

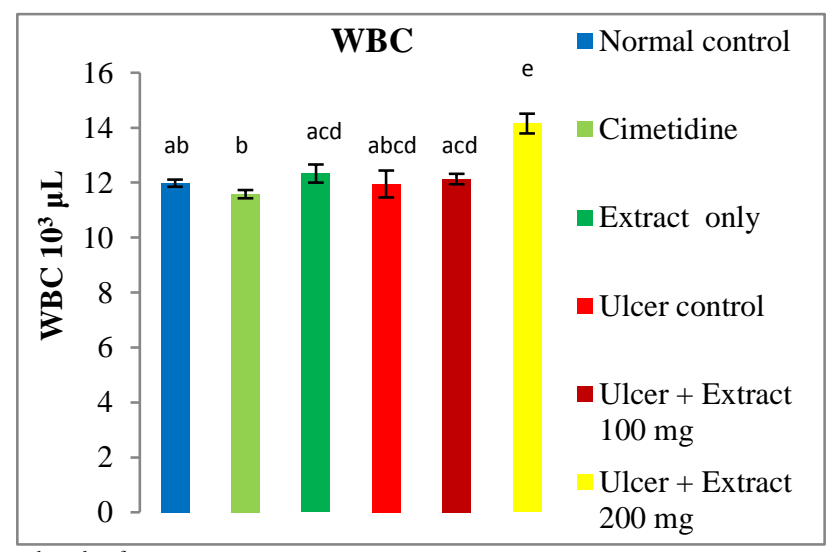

a, b, c, d, e, f statistically significant at $\mathrm{P}<0.05$

Figure 8: WBC counts of indomethacin mediatedgastric mucosa lesion in Wistar rats on administration of $P$. thonningii extract.

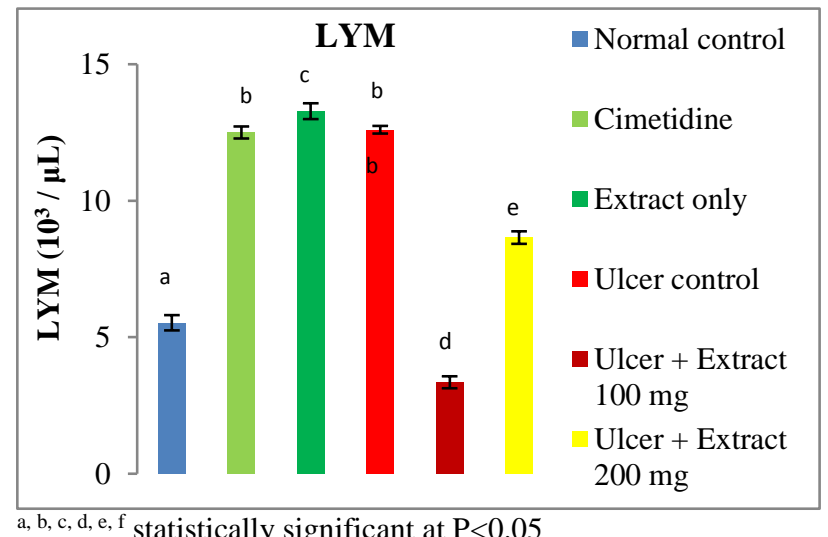

a, b, c, d, e, f statistically significant at $\mathrm{P}<0.05$

Figure 9: LYM concentration of indomethacinmediated gastric mucosa lesion in Wistar rats on administration of $\boldsymbol{P}$. thonningii extract.
The differential white blood cell count showed similar pattern in lymphocytes (Figure 9), neutrophils (Figure 10) and MXD (Figure 11) in the groups. There was significant increase in ulcer control group but with treatment of the ulcer with $P$. thonningii extract, as a significant decrease was obtained. However, compared with the control, the ulcer treated with 100 and $200 \mathrm{mg} / \mathrm{kg}$ bwt of $P$. thonningii extract produced significant $(\mathrm{P}<0.05)$ decrease and increase respectively in the differential white blood cell count suggesting that possible normalisation could occur at about $150 \mathrm{mg} P$. thonningii extract administration.

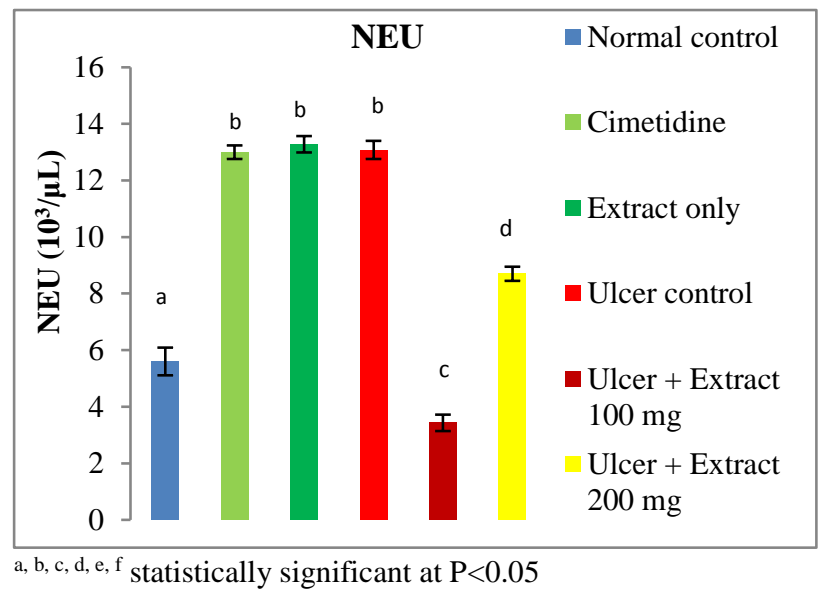

Figure 10: NEU counts of indomethacin- mediated gastric mucosa lesion in Wistar rats on administration of $P$. thonningii extract.

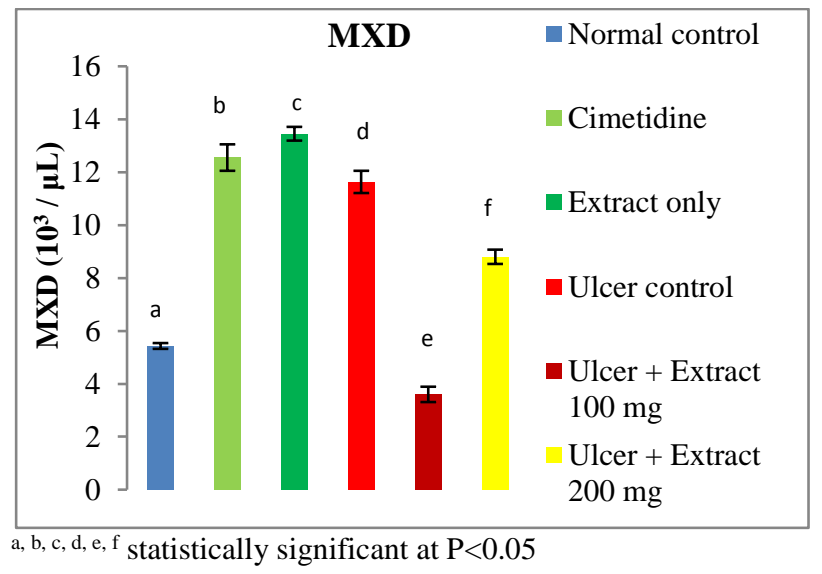

Figure 11: Mixed Cell Count (MXD) concentration of indomethacin mediated gastric mucosa lesion in Wistar rats on administration of $\boldsymbol{P}$. thonningii extract.

\section{DISCUSSION}

The assessment of the haematological parameters of Wistar rats is a valuable tool for monitoring the effect of plant extracts on animal blood chemistry. The haematological parameters can be used to determine the extent of deleterious effect of foreign compounds including plant extracts on the blood constituents of an animal. It can also be used to explain blood related functions of chemical compounds/plant extracts. Such 
analysis is relevant for risk evaluation as the changes in the haematological system have higher predictive value for human toxicity when the data are translated from animal studies. ${ }^{12}$

Gastrointestinal microcirculation and the mucus layer normally maintain the integrity of the gastric mucosa by providing nourishment eliminating hydrogen ion, oxygen radicals and other toxic substances, increasing bicarbonate secretion to neutralize hydrogen ions. ${ }^{13}$ Mucosa damage occurs when the mucosal barrier is compromised and can no longer block the detrimental effects of hydrogen ions and oxygen radicals. ${ }^{14}$

In this present study, there is clear indication that $P$. thonningii extract encourages erythropoiesis. The red blood cell (RBC) count and haemoglobin $(\mathrm{Hb})$ decrease observed following induced gastric ulcer was normalised on administration of $P$. thonningii leaf extract. This is an indication that gastric mediated ulcerative lesions affect erythropoiesis by hindering the release of erythropoietin in the kidney, which is the humoral regulator of $\mathrm{RBC}$ production. ${ }^{15}$ Stress induced gastric ulceration reduces blood parameters such as haematocrit, haemoglobin, erythrocyte count but increased leucocyte count. ${ }^{16}$ This process appears to have been reversed by the extract.

Evaluation of absolute red blood indices showed that the MCV was normalised (from large to normal RBC) after the administration of $200 \mathrm{mg} / \mathrm{kgbwt}$ of the extract on induced gastric ulcer. The increase in $\mathrm{MCH}$ and $\mathrm{MCHC}$ appears to correspond with the RBC count, $\mathrm{Hb}$ and HCT but not an abnormality. This rather means that there was improved oxygen-carrying capacity of the blood on administration of the extract especially at $200 \mathrm{mg} / \mathrm{kgbwt}$ to gastric ulcer induced mucosa lesions.

The WBC count of gastric induced mucosa lesions were normal, but the neutrophil levels were increased. This is in line with reports suggesting that WBC is not altered by gastric ulcer except with age, but neutrophils are. The extract at $100 \mathrm{mg}$ did not alter WBC count on the gastric induced mucosa lesions but did at $200 \mathrm{mg}$. It is very likely it boosts the immune system at that amount.

A spectrum of the differential WBC count showed that the extract exhibited the potential to normalise the neutrophils, lymphocytes and the mixed cell count levels in the serum of the gastric induced ulcer mucosa lesions. However, the platelets counts were further decreased after administration of the extract on ulcer lesions giving indication of thrombocytopenia.

Thrombocytopenia may result from several factors including certain type of medications such as quinine, sulphur-containing antibiotics and anticonvulsants. ${ }^{17}$ The interactive effect between certain agents present in the leaf extract with the ulcer lesions may have confused the immune system and caused it to reduce the platelets counts.

\section{CONCLUSION}

The $P$. thonningii leaf extract showed promising result in addressing decreased levels of RBC and $\mathrm{Hb}$ caused by ulcer. The leaf extract was able to normalise these effects. Except for platelet counts where certain agents in the plant may have caused the immune system to reduce the platelet counts when it interacted with ulcer lesions, the WBC count and differential WBC counts were quite positive. It was able to reverse macrocytosis caused by ulcer lesions to normal, hence exhibiting a haemato-protective nature.

Funding: No funding sources

Conflict of interest: None declared

Ethical approval: The study was approved by the Institutional Ethics Committee of Cross River University of Technology, Calabar, Nigeria

\section{REFERENCES}

1. Srarani P, Jayasia PS, Erhad KP, Nishad KP. Review on natural antiulcer agents. Inter $J$ Pharma and Ind Res. 2011;1(1):67-70.

2. Gadekar R, Singner PK, Chaurasiya PK, Panar RS, Patu UK. A potential of some medicinal plants as an antiulcer agent. Pharmacogn Rev. 2010;4(8):136-40.

3. Hunt HR, Ireneus T, Padol YY. Peptic ulcer disease today: nature clinical practice. Gastroenterol Hepatol 2006;3(2):80-5.

4. Grossman M. Peptic ulcer: A guide for practicing Physicians. Chicago Year book; Medical publication. Amer J Pharm Toxicol. 2009;4(7):89-93.

5. Malfertheirer P. Current Concept in the management of Helicobacter pylori infection The Maastricht, 2000 consensus Report Alient Pharmacol Ther. 2002;16:167-80.

6. Blackman JA. Alternative Medicine. Microsoft Encarta. Redmond, W.A: Microsoft Corporation; 2009.

7. Ighodaro OM, Omole JO. Effects of Nigerian Pilliostigma thonningii species leaf extract on lipid profile in Wistar rats. ISRN Pharmacol. 2012 Sep 6;2012.

8. Dasofunjo K, Nwodo OFC, Johnson JI, Ukpanukpong RU, Ugwu MN, Odinaka E. Haematopoietic effect of ethanolic leaf extract of Piliostigma thonningii on male albino rat. J Nat Prod Plant Resour. 2013;3(2):14

9. Maroyi A. Traditional use of medicinal plants in south-central Zimbabwe: review and perspectives. J Ethnobiol Ethnomed. 2013;9:31-48.

10. Chinsembu KC. Ethnobotanical study of plants used in the management of HIV/AIDS-related diseases in Livingstone, Southern Province, Zambia. Evid Based Complement Alternat Med. 2016;2016.

11. Somasundaram S, Hayllar H, Rafi S, Wrigglesworth JM, Macpherson AJS, Bjarnason I. Review: The Biochemical basis of non-steroidal anti-inflammatory drug-induced damage to the gastrointestinal tract; a 
review and a hypothesis. Scand J Gastroenterol. 1995;30:289-99.

12. Olson H, Betton G, Robinson D, Thomas K, Monro A, Kolaja G, Lilly P, Sanders J, Sipes G, Bracken W, Dorato M, Deun KV, Smith P, Berger B, Heller A. Concordance of toxicity of pharmaceuticals in humans and in animals. Reg Toxicol Pharmacol. 2000;32:5663.

13. Spirt MJ. Stress related mucosal diseases, risk factors and prophylactic therapy. Clin Ther. 2004;26(2):197213.

14. Spirt MJ, Standley S. Update on stress ulcer prophylaxis in critically ill patients. Critical care Nurse. 2006;26(1):18-22-28.

15. Koury MJ, Haase V. H. Anaemia in kidney disease: harnessing hypoxia responses for therapy. Nat Rev Nephrol. 2016;11(7):394-410.
16. Gbore FA, Oginni O, Adewole AM, Aladeran JO. The effects of transportation and handling stress on haematological and plasma biochemistry in fingerlings of Ciarias gariepinus and Tilapia zill. World J Africa Sci. 2006;2(2):208-12.

17. Arnold DM, Kukaswadia S, Nazi L, Esmail A, Dewar L, Smith JW, et al. A systematic evaluation of laboratory testing for drug- induced immune thrombocytopenia. J Thromb Haemost. 2013;11(1):169-76.

Cite this article as: Asuk AA, Dasofunjo K, Ugwu $\mathrm{MN}$, Adie FO. The haemato-protective effect of Piliostigma thonningii leaf extract on indomethacininduced gastric mucosa ulcer in rats. Int J Basic Clin Pharmacol 2018;7:1454-9. 